\title{
LIQUIDITY OF BITCOIN - INSIGHTS FROM POLISH AND GLOBAL MARKETS
}

\section{INTRODUCTION}

Cryptocurrencies have recently received much publicity. According to the European Central Bank, they can be defined as 'a digital representation of value, not issued by a central bank, credit institution or e-money institution, which, in some circumstances, can be used as an alternative

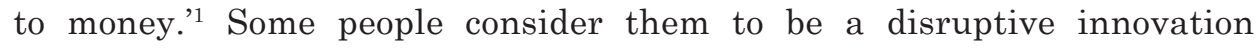
which can revolutionize payment systems. However, others view them as an invention used for money laundering or tax evasion and as a threat to financial stability. Despite these ambiguous approaches, the popularity of cryptocurrencies has grown rapidly, resulting in an increase of trading volume and extensive media coverage.

The most renowned example of cryptocurrencies is bitcoin, which was introduced by Satoshi Nakamoto ${ }^{2}$ - a person or a group of people whose real identity is not known. Its creator(s) envisaged bitcoin as a peer-to-peer version of electronic money which would enable online payments to be made via an electronic payment system based on cryptographic proof (instead of trust) and without financial intermediaries. This initiative led to the emergence of a whole ecosystem comprised of different participants (for example miners responsible for validating transactions, entities making and accepting bitcoin payments, bitcoin investors and cryptocurrency intermediaries) as well as their mutual interactions.

Currently, speculation has supplanted the original purpose of the use of bitcoin. As noted by Trimborn, Li and Härdle, ${ }^{3}$ cryptocurrencies are less liquid than traditional assets and thus investors, wishing to include them in their portfolios, need to take into account the potential liquidity constraints. Liquidity is, therefore, an important feature of the market which should be considered by investors. It is also worth noting that since the Bitcoin ${ }^{4}$ network is not centralized and has no barriers in the form of state borders, its idea has spread around the world and thus also reached Poland.

\footnotetext{
${ }^{1} \mathrm{ECB}(2015)$.

${ }^{2}$ Nakamoto (2008).

${ }^{3}$ Trimborn, Li, Härdle (2017).

${ }^{4}$ When referring to the Bitcoin system - a capital B is used, when to the unit of cryptocurrency used within this system - bitcoin, a lower case letter is used.
} 
The main aim of this article is to characterize and compare big and small bitcoin markets in terms of liquidity. I study four platforms, which are characterized by high trade volume - Kraken, Bitstamp, BitFlyer and BTCBOX, as well as small entities which enable the trade of bitcoin in Polish zloty - BitBay and BitMarket. I use the intraday and daily data from July 2017 to mid-March 2019. This period encompasses the biggest boom on the bitcoin market and the successive downward price trend. Based on these data, I compare the number of trades and the time between trades on different bitcoin markets, determine the volume distribution throughout the day and examine the dynamics of Amihud's illiquidity measure - ILLIQ. In the article, the quantitative data are presented as of March 2019, whereas the information from the websites of cryptocurrency platforms - as of May 2019.

The article is structured as follows - the second section provides a review of the literature related to the Bitcoin ecosystem, with particular emphasis on cryptocurrency exchanges. In the third section, I characterize selected platforms and the data set used in the analysis. Then, I briefly describe the notion of liquidity and its measures that I use. In the last section, I discuss the results, and after that, I conclude.

\section{LITERATURE REVIEW}

Bitcoin is a distributed, peer-to-peer system, which means that it is not based on one central server. The units used by participants within this system are called bitcoins. They are created by 'miners' who use the processing power of their computers to verify the transactions and record them in the ledger. The ownership of bitcoin units is proven in the network by so-called 'keys'. Thanks to them, their owners can sign transactions and spend their bitcoins by making a transfer to another user. ${ }^{5}$

With regards to payments, the cryptocurrency market can be considered a special case of a two-sided market. This means that a transaction will be made only if both a payer and a payee agree to use this particular cryptocurrency. The higher the number of retailers accepting crypto-payments, the more attractive to the customers the cryptocurrency becomes. At the same time, the retailers become more likely to accept this particular cryptocurrency, the higher its adoption rate among the consumers is. ${ }^{6}$ Therefore, a large and wellconnected group of users is crucial for the survival of bitcoin and other peerto-peer cryptocurrencies. ${ }^{7}$ Polasik et al. ${ }^{8}$, on the basis of a survey carried out

\footnotetext{
${ }^{5}$ Antonopoulos (2018): 31.

6 Jonker (2018).

7 Teo (2015).

8 Polasik et al. (2015).
} 
among retailers accepting bitcoin payments for online transactions, find that its rate of acceptance is higher in the countries with a low GDP per capita and a larger shadow economy. The authors also stress that the customers with knowledge about this innovation are more willing to use bitcoin. Moreover, their results show that PayPal, cash-on-delivery and payment cards serve as substitutes for bitcoin, whereas Pay-By-Link is its complement. Jonker, ${ }^{9}$ also on the basis of survey data collected from retailers selling their products online, finds that consumer demand, net transactional benefits and the perceived adoption effort affect the acceptance of bitcoin among respondents. She identifies the lack of consumer demand as the most significant barrier to the acceptance of cryptocurrencies. The results she presents also suggest that cryptocurrency owners do not use bitcoin for online payments. As a result, it is unlikely that its adoption will increase substantially and significantly change the existing retail payment system.

There is some evidence in the literature that bitcoin neither serves as a medium of exchange nor fulfils other crucial functions of money - a unit of account and a store of value. ${ }^{10}$ It is perceived by many rather as an investment tool and some researchers imply that it resembles a speculative investment. ${ }^{11}$ Due to its negative or zero correlation with traditional types of assets classes, like for example stocks, bonds, commodities or currencies, adding bitcoin to the portfolio may lead to risk reduction and, therefore, be useful in portfolio diversification. ${ }^{12}$

The marketplace for trading cryptocurrencies is offered by entities which are commonly called exchanges. They provide services like buying and selling cryptocurrencies in exchange for national currencies as well as for other cryptocurrencies. Thus, they play an extremely important role in the cryptocurrency economy. ${ }^{13}$

One of the important features of the bitcoin market is its great degree of fragmentation - there are many different cryptocurrency trading platforms. The first one was established in 2010. ${ }^{14}$ As of the end of March 2019, CoinMarketCap.com listed 218 cryptocurrency exchanges. ${ }^{15}$ It is worth noting that these entities do not create a homogeneous group. Hileman and Rauchs ${ }^{16}$ analyse 51 exchanges located in 27 countries. They find that the global cryptocurrency trade volumes are dominated by a few large exchanges. The authors also identify some differences between the small and the large platforms. Only 35\% of large exchanges hold a formal government licence.

\footnotetext{
9 Jonker (2018).

10 ECB (2015): 23.

11 Glaser et al. (2014); Yermack (2015); Baur et al. (2018).

12 Pandey, Wu (2014); Briere et al. (2015); Carrick (2016); Azzi et al. (2017); Baur et al.

13 Hileman, Rauchs (2017): 30.

14 Brandvold et al. (2015).

15 CoinMarketCap (2019).

16 Hileman, Rauchs (2017).
} (2018). 
This number is much higher (52\%) among small exchanges. Moreover, small entities seem to have a limited cryptocurrency offer $-73 \%$ of them list one or two cryptocurrencies, whereas $73 \%$ of large exchanges have two or more cryptocurrencies in their offer. Trading bitcoin, however, is supported by all the study participants. Security of funds is another important aspect of cryptocurrency trading. Exchanges make use of various internal security measures, such as cold storage or a multi-factor authentication. Another distinguishing feature is the control over the keys $-73 \%$ of study participants take custody of user funds and $23 \%$ let users control the keys. Only slightly more than half of the analysed small custodial exchanges prepared a written policy indicating what will happen to the customers' funds in the case of their loss due to a security breach. In the case of large custodial exchanges, this percentage was higher (78\%). ${ }^{17}$

According to the estimates of Bhaskar and Lee presented in 2015, ${ }^{18} 45 \%$ of cryptocurrency exchanges eventually shut down. Transaction volume, financial strength, security breach, backroom and settlement support, as well as compliance capabilities, are among the factors determining the survival time of these entities. Moore and Christin ${ }^{19}$ find that more popular exchanges are less likely to be closed; however, they are more likely to face a security breach than less popular entities. Referring to security breaches, Bhaskar and Lee ${ }^{20}$ note that most cryptocurrency exchanges are undercapitalized, as the majority of them are not subject to the capital adequacy requirements imposed by financial regulations. In an event of a security breach, they would not be able to manage the loss. Brandvold et al. ${ }^{21}$ analyse the role of selected cryptocurrency exchanges in the price discovery of bitcoin between April 2013 and February 2014. They identify Mt. Gox and BTC-e as the leaders at that time. The authors also note that small exchanges have a smaller information share and they usually lag behind the market.

Liquidity is one of the important aspects in cryptocurrency trading and, although limited, it has received attention in the literature. Loi ${ }^{22}$ scrutinizes the liquidity of five exchanges which enable trading bitcoin in U.S. dollars and compares them in this respect to selected stock indexes. Dimpfl ${ }^{23}$ looks at the bitcoin market from the perspective of liquidity and adverse selection, and finds the eight analysed markets to be fairly liquid. He notes that both the spread and its proportion related to the adverse selection costs are high. This might suggest that private information is important for the bid-ask spread formation. The liquidity of the bitcoin market is also the subject of

\footnotetext{
17 Hileman, Rauchs (2017).

18 Bhaskar, Lee (2015).

19 Moore, Christin (2013).

${ }^{20}$ Bhaskar, Lee (2015).

21 Brandvold et al. (2015).

${ }^{22}$ Loi (2018).

${ }^{23}$ Dimpfl (2017).
} 
Shi's research ${ }^{24}$, who analyses the time series from Bitstamp, and notices that bitcoin futures trading has contributed to the improvement of the spot market liquidity and stabilized the spot price volatility. Brauneis and Meste $^{25}$ link liquidity measures with the market efficiency, finding that the higher the liquidity of the analysed cryptocurrencies, the more efficient they become.

The research on the Polish bitcoin market is rather scant. Among the few exceptions is the study of Piotrowska ${ }^{26}$, who describes Polish bitcoin users and their purposes in using this cryptocurrency, and of Poskart ${ }^{27}$, who compares the offers of five cryptocurrency platforms operating in Poland.

\section{SELECTED CRYPTOCURRENCY EXCHANGES AND THE DATA}

In this article, I analyse platforms which enable exchanging bitcoin for four traditional currencies - Japanese yen (JPY), U.S. dollar (USD), euro (EUR), and Polish zloty (PLN). The data were extracted from the website Bitcoincharts.com. According to this website, within the last 30 days (as of 27 March 2019), 55\% of volume in the bitcoin market was exchanged in USD, $19 \%$ - in JPY and 13\% - in EUR. These currencies were followed by: PLN, AUD (Australian dollar), IDR (Indonesian rupiah), BRL (Brazilian real) and ZAR (South African rand).

The analysed six platforms were selected based on the availability of both transactional and daily data, their location and the traditional currencies in their offer. Out of the exchanges that are covered by Bitcoincharts.com, BitFlyer and BTCBOX (based in Japan) are among the most significant players in trading bitcoin in JPY, Kraken (based in the USA) is the market which excels in terms of trading bitcoin in EUR, and Bitstamp (based in the UK) is the biggest exchange in terms of USD volume. BitBay and BitMarket dominate trading bitcoin in PLN.

These entities enable exchanging bitcoin for several different currencies. I took this fact into account and, based on the available data, for USD I analysed datasets from Bitstamp, Kraken and BitBay, for EUR - from Kraken, BitBay and BitMarket, for JPY - from BitFlyer, BTCBOX and Kraken and for PLN from BitBay and BitMarket. Basic information related to these cryptocurrency markets is presented in Table 1.

\footnotetext{
24 Shi (2017).

25 Brauneis, Mestel (2018).

26 Piotrowska (2018).

27 Poskart (2017).
} 


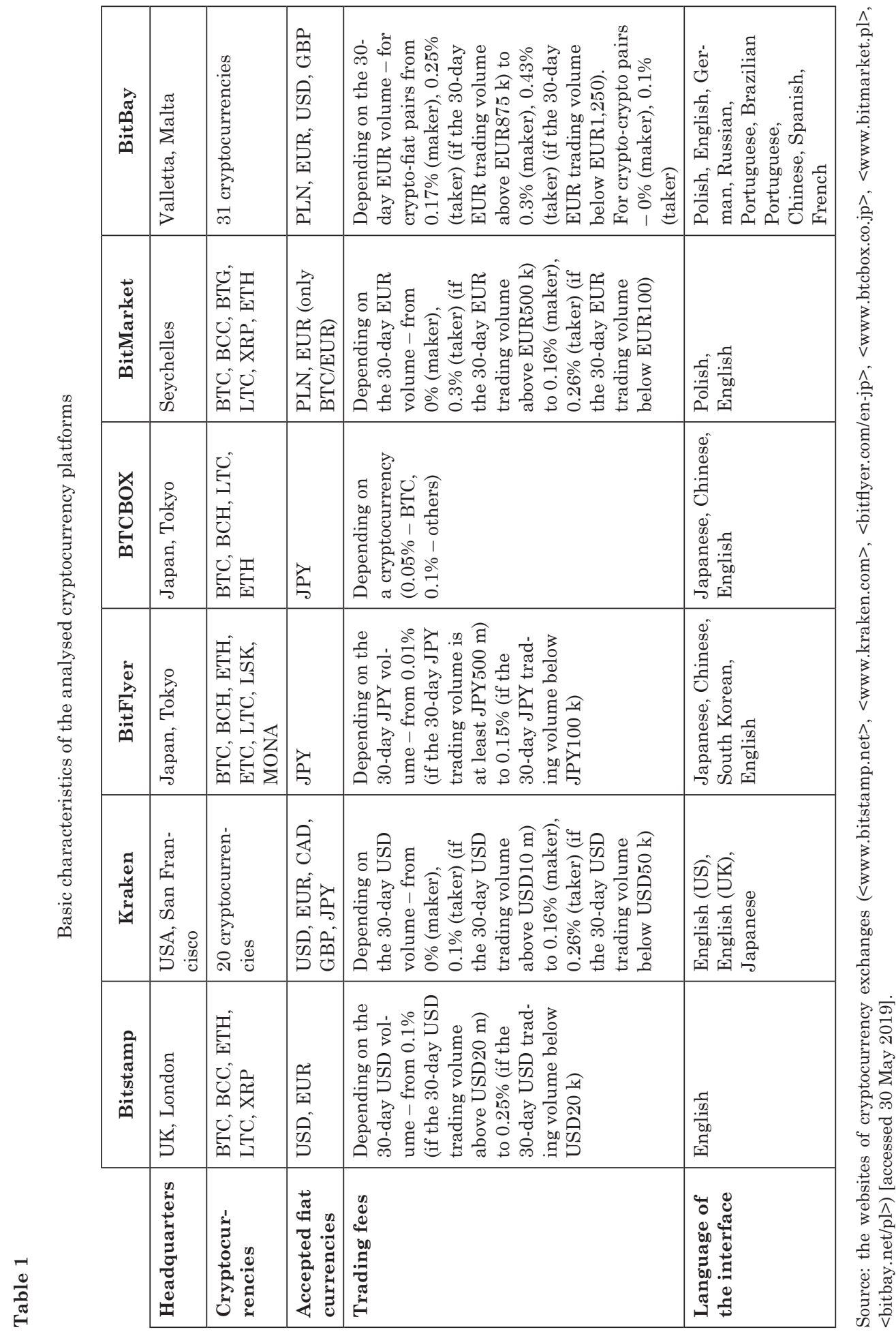


Out of the analysed platforms, BitBay is distinguished by the number of cryptocurrencies in its offer and the number of languages that its interface is available in. This platform, together with BitMarket, are the only ones which have their websites in Polish. This may be their competitive advantage. The interface of the remaining platforms is available either in English or in one of the Asian languages.

The trading fee schedule usually depends on the trading volume and the type of the order - the fees are higher in the case of orders which provide liquidity (maker) and lower in the case of the ones which take it (taker). Platforms which enable trading in PLN also use such a fee schedule. In their case, the investors whose 30-day trading volume exceeds EUR500,000 (BitMarket) or EUR875,000 (BitBay) can count on fees which are lower than the fees paid by retail investors. These limits are rather low, compared to the biggest exchanges. This may suggest that BitBay and BitMarket serve mainly local and retail investors.

I used two types of data sets - with transactional and daily observations. To focus on the greatest boom on the bitcoin market and the subsequent downturn, I analysed the data from 5 July 2017 to 17 March 2019. Another reason for selecting such a period is the fact that the characteristics of the Bitcoin system change very often, as shown by Thies and Molnár. ${ }^{28}$ The average bitcoin prices in USD noted on selected markets over the analysed time are presented in Graph 1.

Graph 1

Average bitcoin prices in USD (from Bitstamp, Kraken, and BitBay)

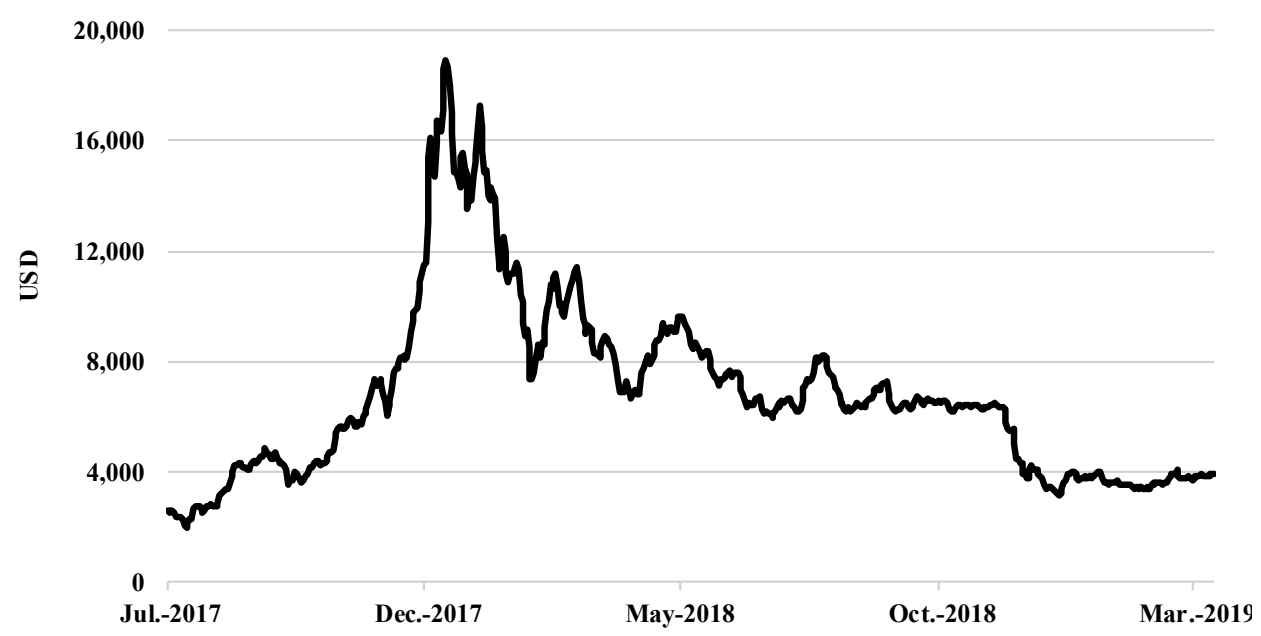

Source: based on the data sourced from <Bitcoincharts.com> [accessed 18 March 2019].

28 Thies, Molnár (2018). 


\section{LIQUIDITY}

Harris $^{29}$ called liquidity 'the most important characteristics of wellfunctioning markets.' It is a notion which is difficult to define, let alone to estimate. ${ }^{30}$ According to Black, ${ }^{31}$ 'in general, an asset is said to be liquid if it can be sold in a short time, at a price not too much below the price the seller would get if he took plenty of time to sell the asset.' He further developed this idea with respect to stocks, which can be generalized to other types of assets. He noted that a liquid market can be perceived as a continuous one, which means that an investor is able to immediately buy or sell almost any amount of stocks, and as an efficient one - an investor can buy or sell a small number of stocks near the current market price and a large number of stocks over a long period at prices which, on average, are close to the current market price. ${ }^{32}$

Liquidity cannot be observed directly and, due to its multidimensional nature, it is not possible to capture it in a single measure. ${ }^{33}$ Trading volume - the number of sold instruments, is a direct liquidity measure, and one of the most commonly used. ${ }^{34}$ In this study, I also take into account the average number of trades, the waiting time between trades, and ILLIQ - an illiquidity measure introduced by Amihud ${ }^{35}$ which combines return with volume. This relation reflects the price change, resulting from one currency unit volume. It was calculated using the following formula: ${ }^{36}$

$$
I L L I Q_{t}=\frac{\left|R_{t}\right|}{\log \left(V O L D_{t}\right)},
$$

where $\left|R_{t}\right|$ denotes the absolute return over a day, $t$, which in this study was calculated based on daily weighted prices, while $V O L D_{t}$ is the volume in currency units within a day $t$. The higher its values, the lower the liquidity.

\section{EMPIRICAL RESULTS}

In the first step, I examined the transactional data. The overall number of trades within the analysed time, the daily average number of trades and the average time between trades are presented in Table 2 .

\footnotetext{
29 Harris (2003).

${ }^{30}$ Lesmond (2005).

31 Black (1971).

32 Black (1971).

33 Amihud (2002).

${ }^{34}$ Doman (2011): 28.

35 Amihud (2002).

${ }^{36}$ Będowska-Sójka, Echaust (2018).
} 
Table 2

The number of trades and the time between trades in different bitcoin markets

\begin{tabular}{|c|c|c|c|c|c|}
\hline \multirow{2}{*}{ Market } & \multirow{2}{*}{ Currency } & \multicolumn{2}{|c|}{ The number of trades } & \multicolumn{2}{|c|}{$\begin{array}{l}\text { The time between trades } \\
\text { (seconds) }\end{array}$} \\
\hline & & Overall & $\begin{array}{c}\text { Daily } \\
\text { average }\end{array}$ & Mean & $\begin{array}{l}\text { Standard } \\
\text { deviation }\end{array}$ \\
\hline Bitstamp & USD & $17,839,443$ & 28,727 & 3 & 8 \\
\hline Kraken & USD & $11,269,228$ & 18,147 & 5 & 68 \\
\hline BitBay & USD & 168,196 & 271 & 319 & 1,560 \\
\hline Kraken & EUR & $17,718,832$ & 28,533 & 3 & 66 \\
\hline BitBay & EUR & 227,392 & 366 & 236 & 867 \\
\hline BitMarket & EUR & 16,837 & 27 & 3,108 & 10,076 \\
\hline BitFlyer & JPY & $39,893,976$ & 64,242 & 1 & 57 \\
\hline BTCBOX & JPY & $9,130,116$ & 14,702 & 6 & 28 \\
\hline Kraken & JPY & 146,097 & 235 & 366 & 2,301 \\
\hline BitBay & PLN & $3,882,415$ & 6,252 & 14 & 55 \\
\hline BitMarket & PLN & 785,007 & 1,264 & 68 & 279 \\
\hline
\end{tabular}

Source: author's calculations based on the data sourced from <Bitcoincharts.com> [accessed 18 March 2019].

BitFlyer (JPY), Bitstamp (USD) and Kraken (EUR) are the leaders in this respect, whereas BitMarket (EUR), Kraken (JPY) and BitBay (USD) are ranked the lowest. The fact that one exchange dominates in trading in a particular currency does not mean that it excels in terms of trading in other currencies as well. This is shown by the example of Kraken. Although it is highly active in trading bitcoin in EUR and USD, it does not seem to be very liquid in terms of trading in JPY.

Based on transactional data, it is possible to determine the volume distribution throughout the day. The results, expressed as the percentage of the total daily volume, are presented in Graphs 2-12. The time on the horizontal axes is UTC.

One of the stylized facts about stock markets is the U-shaped volume periodicity. It results from the normal cycle of the investors' activity - it is higher at the beginning and at the end of the trading session and significantly decreases in the middle of the day, during lunch time ${ }^{37}$ On the basis of a set of bitcoin markets which is different than the one analysed in this article, Dimpf ${ }^{38}$ finds that the liquidity of bitcoin exchanges is highest during the opening hours of respective stock markets. He also notes that the liquidity of these markets depends on the time of the day, although the effect is less pronounced than in the case of stock markets. This may result from the continuous possibility of trading bitcoin (24/7).

\footnotetext{
37 Doman (2011): 202.

38 Dimpfl (2017).
} 
Graph 2-12

The hourly distribution of trading volume across different bitcoin markets. Time axis - UTC

Bitstamp (USD)

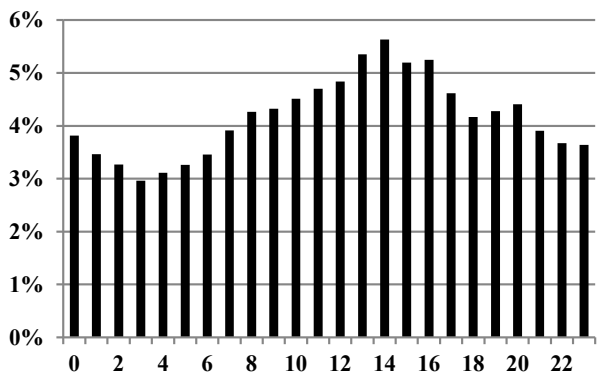

BitBay (USD)

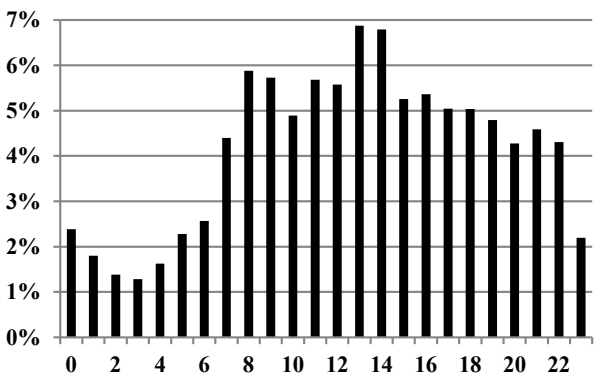

BitBay (EUR)

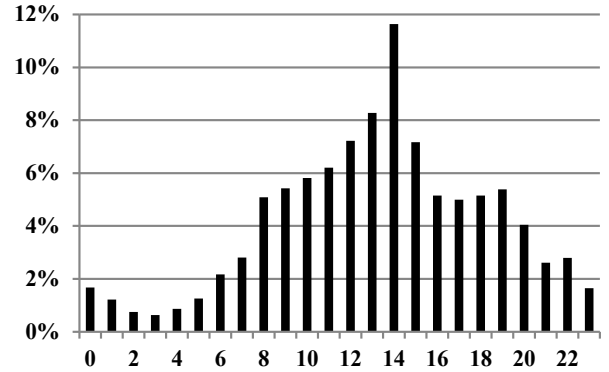

BitBay (PLN)

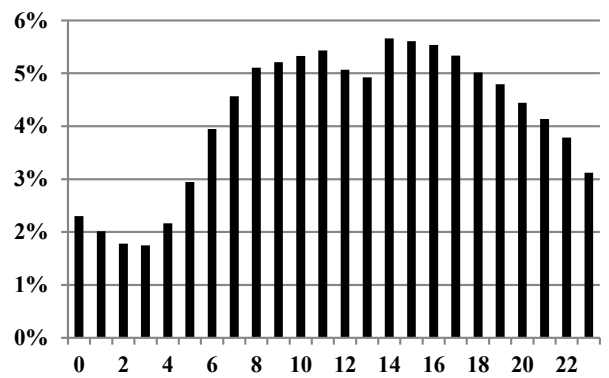

Kraken (USD)

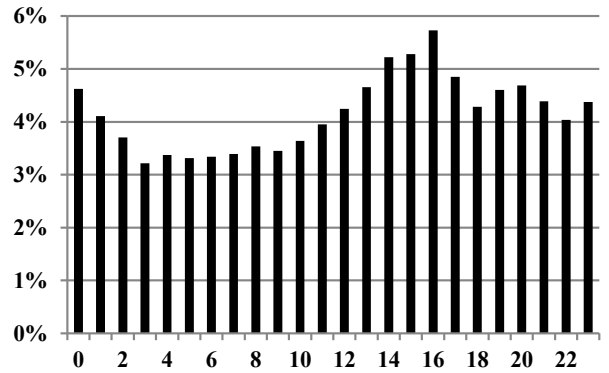

Kraken (EUR)

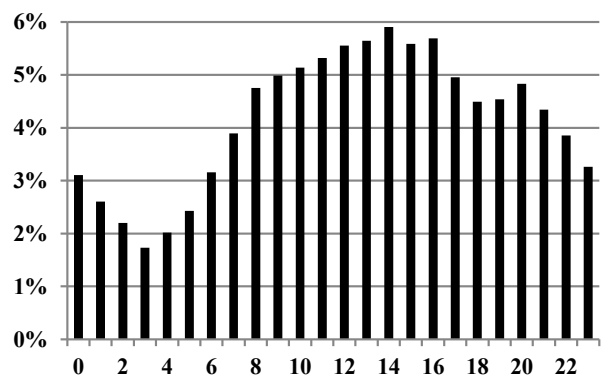

BitMarket (EUR)

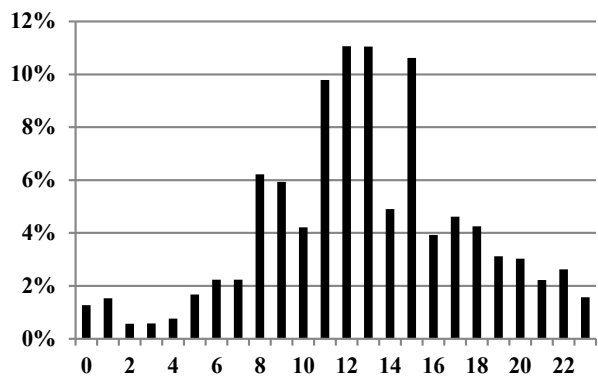

BitMarket (PLN)

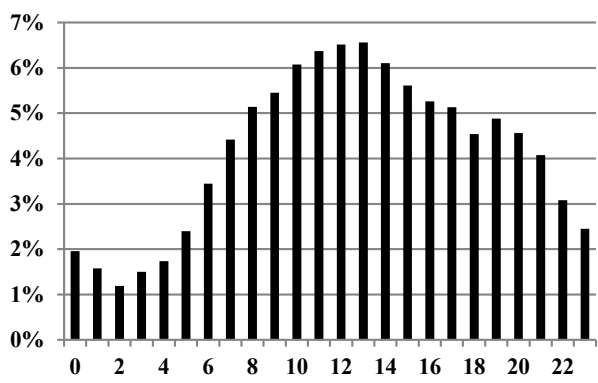


BitFlyer (JPY)

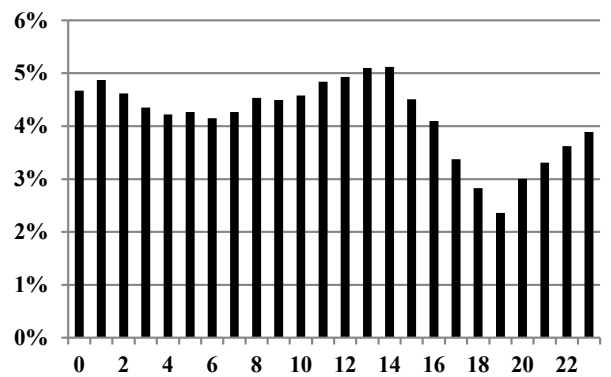

BTCBOX (JPY)

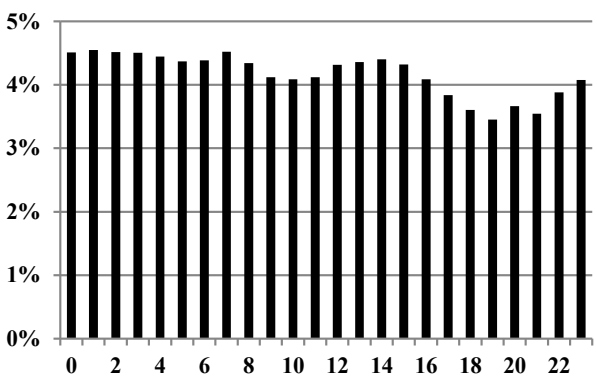

Kraken (JPY)

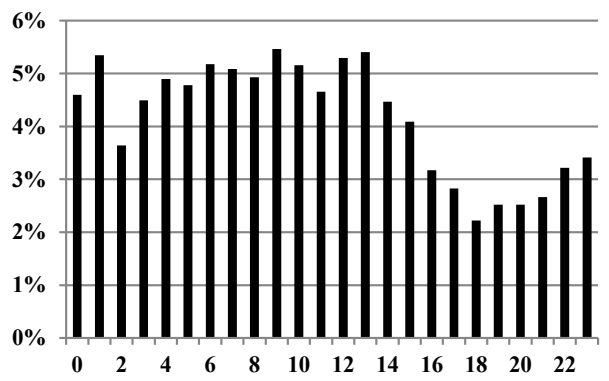

Source: author's calculations based on the data sourced from <Bitcoincharts.com> [accessed 18 March 2019].

As shown in Graphs 2-12, some markets exhibit a more uniform distribution of volume throughout the day than the others. BTCBOX (JPY) is the most distinct example. It is also noticeable in the case of Bitstamp (USD), Kraken (USD) and BitFlyer (JPY) and may suggest that these markets are used on a global scale to a greater extent than the others.

Moreover, the trade intensity of the markets seems to be related with the activity of human life - generally, trading is more intense during the day-time in a particular part of the world. As far as the exchanges based in the UK and in the USA are concerned, we may observe that trade volumes on Bitstamp (USD) and Kraken (EUR) exhibit a similar pattern - they are the lowest at 3 a.m. UTC and rise gradually, achieving the highest values at around 1-4 p.m. UTC (Bitstamp) and $2-4$ p.m. (Kraken). This may imply that European investors use these markets on a wider scale, as this pattern corresponds to the day- and night-times in Europe. Trading activity on Kraken (USD) is lower between 3 and 10 a.m. UTC. Later, it increases and reaches its peak at 4 p.m. UTC (it is 11 a.m. in New York).

Markets which allow for trading bitcoin in JPY are most active from midnight (UTC) to: 1 p.m. UTC (Kraken), 2 p.m. UTC (BitFlyer) and 3 p.m. (BTCBOX). The time zone in Japan is UTC+9. This means that these markets are most active from 9 a.m. to 10 p.m. - midnight JST (Japanese Standard Time), and less active during the night-time in Japan.

Generally, BitBay and BitMarket are most active from 6 a.m. UTC. This holds irrespective of the currency that the bitcoin is exchanged for. Trading in 
USD (on BitBay) and in PLN (both on BitBay and BitMarket) is also relatively intense until 9-10 p.m. These platforms are also used for trading in euro, however, most of the trades occur between 8 a.m. and 3 p.m. UTC. The specific distribution of the trading volume on these markets may result from the low number of trades, as shown in Table 2. During the night-time in Poland, the activity of BitBay and BitMarket decreases, which may imply that they are used mainly by investors based in Poland.

In the next step, I calculated Amihud's illiquidity measure - ILLIQ, based on daily data. Lower values indicate the higher liquidity of a market. Since this liquidity proxy exhibited significant volatility and jumps, it was smoothed using a 30-day moving average. Table 3 contains the descriptive statistics of ILLIQ and Graphs 13-16 present how this measure developed in the analysed markets over time.

Table 3

Descriptive statistics of ILLIQ

\begin{tabular}{|l|c|c|c|c|c|}
\hline \multicolumn{1}{|c|}{ Market } & Currency & Mean & Min. & Max. & $\begin{array}{c}\text { Standard } \\
\text { deviation }\end{array}$ \\
\hline Bitstamp & USD & 0.004 & 0.001 & 0.007 & 0.002 \\
\hline Kraken & USD & 0.004 & 0.001 & 0.008 & 0.002 \\
\hline BitBay & USD & 0.006 & 0.002 & 0.012 & 0.002 \\
\hline Kraken & EUR & 0.004 & 0.001 & 0.008 & 0.002 \\
\hline BitBay & EUR & 0.006 & 0.002 & 0.011 & 0.002 \\
\hline BitMarket & EUR & 0.008 & 0.002 & 0.017 & 0.003 \\
\hline BitFlyer & JPY & 0.003 & 0.001 & 0.006 & 0.001 \\
\hline BTCBOX & JPY & 0.003 & 0.001 & 0.006 & 0.001 \\
\hline Kraken & JPY & 0.005 & 0.001 & 0.009 & 0.002 \\
\hline BitBay & PLN & 0.003 & 0.001 & 0.007 & 0.002 \\
\hline BitMarket & PLN & 0.004 & 0.001 & 0.009 & 0.002 \\
\hline
\end{tabular}

Source: author's calculations based on the data sourced from <Bitcoincharts.com> [accessed 18 March 2019].

The values of ILLIQ display a similar pattern over the analysed period in the case of all the selected markets. The liquidity decreased at the turn of 2017 and 2018. It was the time when the biggest boom and the subsequent crash in the history of the bitcoin market could be observed. Then the liquidity increased until mid-November 2018. Again, at the turn of the years, the liquidity declined. This time, the rise of the ILLIQ values was accompanied by a slump in bitcoin prices. In February 2019 the liquidity went back to the pre-crash levels. 
Graph 13-16

Daily values of ILLIQ

USD

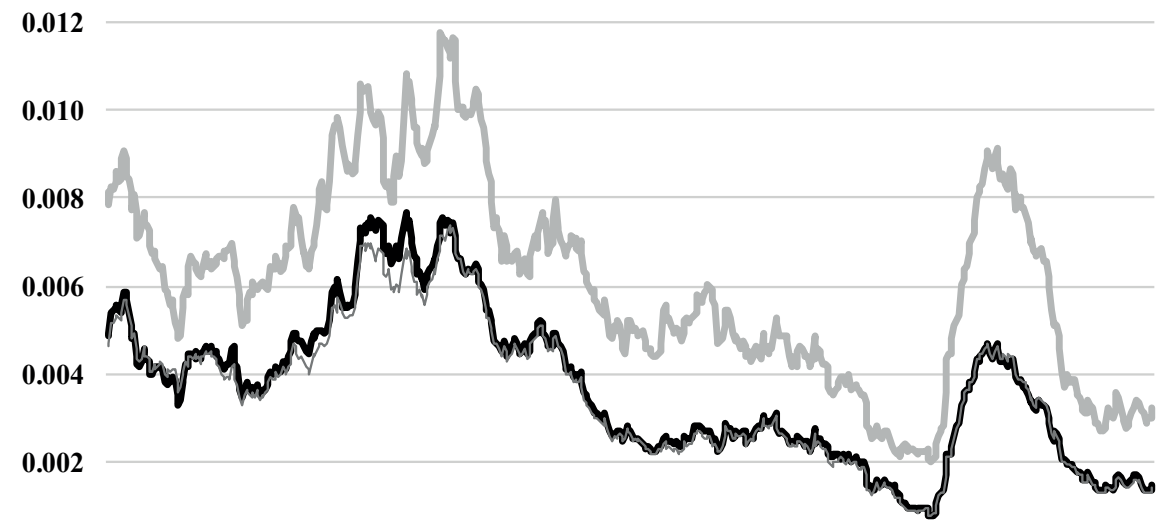

0.000

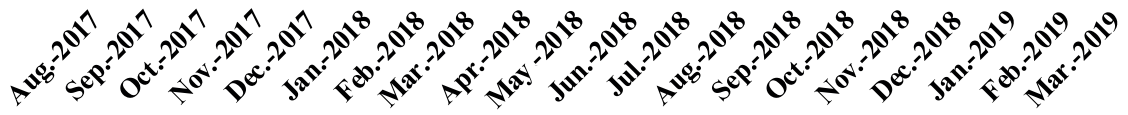

Kraken $\longrightarrow$ BitStamp BitBay

\section{EUR}

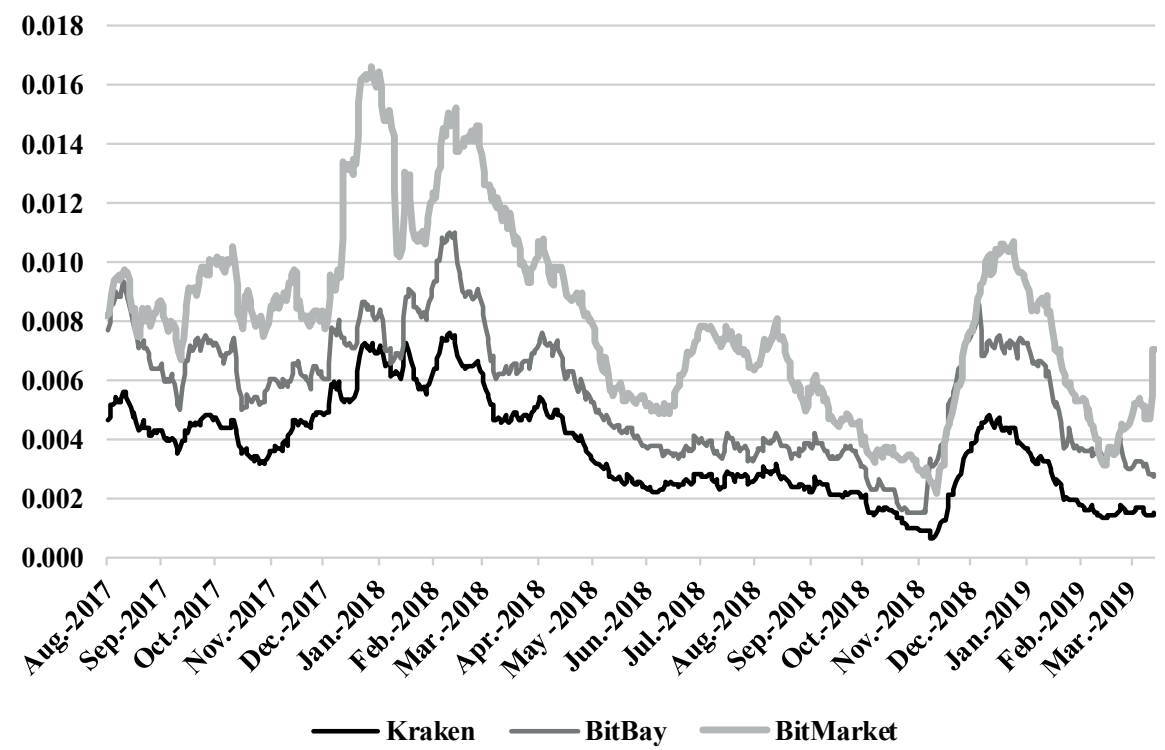


JPY

0.010

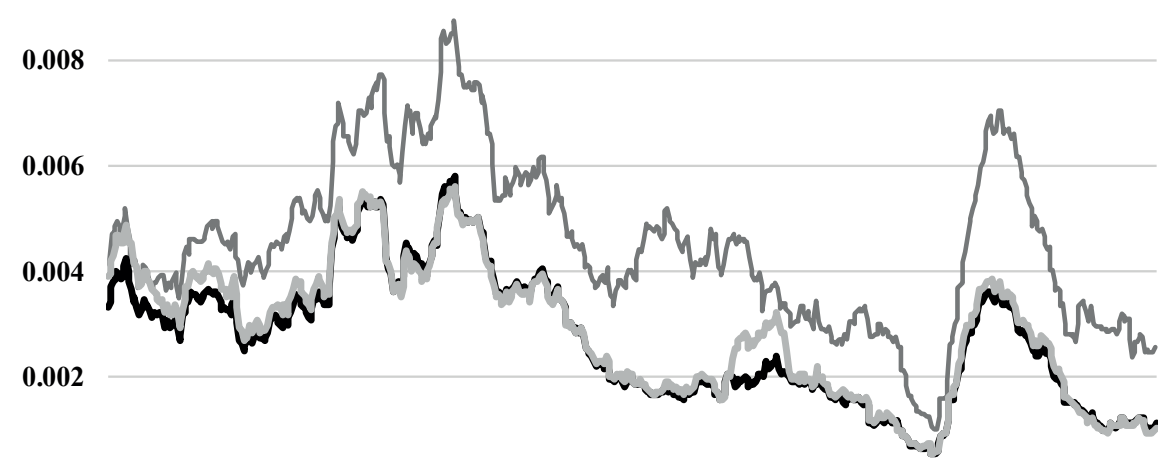

0.000

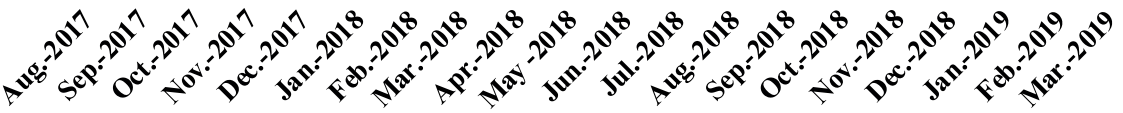

Kraken $\longrightarrow$ BitFlyer $\longrightarrow$ BTCBOX

PLN

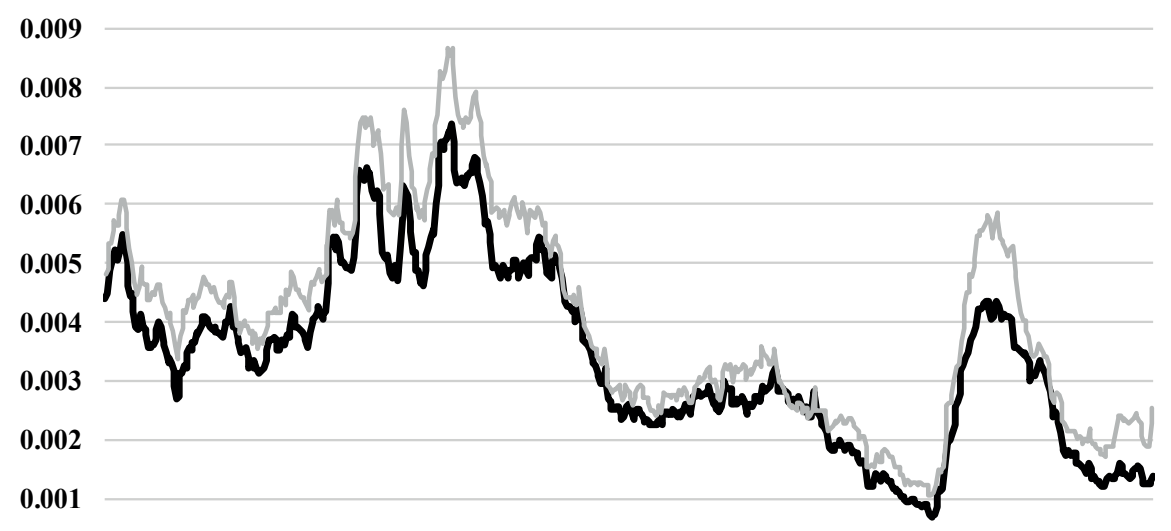

0.000

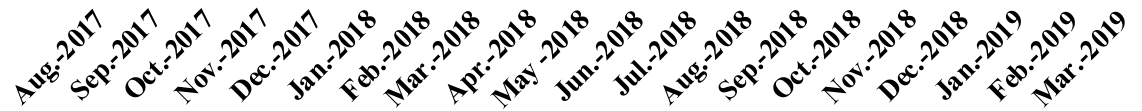

- BitBay $\longrightarrow$ BitMarket

Source: author's calculations based on the data sourced from <Bitcoincharts.com $>$ [accessed 18 March 2019]. 
The Polish bitcoin markets - BitBay (PLN) and BitMarket (PLN) - were fairly liquid in the analysed period. BitBay tended to slightly outperform BitMarket in this respect. Notwithstanding, Graphs 13-16 indicate that these two platforms specialize in trading bitcoin in PLN and are not so liquid with regards to other currencies. This is also the case for Kraken. This cryptocurrency exchange is among the biggest platforms in terms of trading in EUR, and relatively big in terms of trading in USD. Although it also offers the possibility of trading in JPY, it was much less liquid compared to BitFlyer and BTCBOX. The fact that a cryptocurrency platform may be perceived as a global player in terms of trading bitcoin in one currency does not have to mean that it plays an important role in trading in other traditional currencies that are in its offer.

\section{CONCLUDING REMARKS}

Bitcoin was created to facilitate online payments. Currently, however, it is used mainly as an investment vehicle. In this article, I analysed liquidity patterns on different bitcoin exchanges, as liquidity is a factor of great importance for investors. Apart from the platforms which enable the investors to trade bitcoin in USD and EUR, I also examined the markets where it is possible to trade in JPY and PLN.

The analysis of trading activity shows that out of the multitude of bitcoin markets, we can distinguish entities which are renowned globally and entities which are recognized only locally. Although BitBay and BitMarket are the leaders in trading bitcoin in PLN, they undoubtedly belong to the second group.

Moreover, an exchange which is among the global leaders in terms of trading in one currency can be perceived as a smaller market in terms of trading in another currency. It can be also noticed that BitBay and BitMarket are used mainly for trading in PLN. They are rather illiquid in terms of trading in other currencies and their liquidity further decreases at night-time in Poland. They are characterized by a much lower number of trades and, consequently, by a longer time between trades, compared to the biggest platforms. This is further confirmed by the analysis of the Amihud's illiquidity measure which also shows that all the exchanges display similar patterns when the dynamics of this measure is concerned.

As mentioned in the article, as of March 2019, PLN was the fifth most popular currency used for trading bitcoin (according to the data of Bitcoincharts.com). Therefore, the results imply that trading in the bitcoin market is highly concentrated and the distance between leading traditional currencies and PLN is vast, despite the fact that PLN occupies a relatively high place in the ranking.

The competitive advantage of the local platforms, such as BitBay and BitMarket, may result from the fact that they also offer cryptocurrency trading in less popular currencies, not only in the world reserve ones. Moreover, their interfaces are available in local languages (in this case in Polish), which makes 
them more user-friendly. Home bias may contribute to their popularity as well - the cryptocurrency exchanges which enable trading in PLN may seem to be an obvious choice for some Polish investors. Therefore, the fourth industrial revolution, which contributed to the creation of the Bitcoin ecosystem, leaves room for both the big and the local exchanges.

Katarzyna Wtosik

Poznań University of Economics and Business

katarzyna.wlosik@ue.poznan.pl

https://orcid.org/0000-0002-7546-6601

Antonopoulos, A.M. (2018). Mastering Bitcoin. O’Reilly Media. <https://github.com/bitcoinbook/ bitcoinbook> [accessed 13 March 2019].

Amihud, Y. (2002). Illiquidity and stock returns: cross-section and time-series effects. Journal of Financial Markets 5: 31-56.

Azzi, G., Bouri, E., Hagfors, L.I., Molnár, P., Roubaud, D. (2017). On the hedge and safe haven properties of bitcoin: is it really more than a diversifier? Finance Research Letters 20: 192-198.

Baur, D.G., Hong, K., Lee, A.D. (2018). Bitcoin: medium of exchange or speculative assets? Journal of International Financial Markets. Institutions and Money 54: 177-189.

Będowska-Sójka, B., Echaust, K. (2018). Commonality in liquidity and the dynamics of the liquidity indices: the evidence from the emerging European stock markets. <https://www. researchgate.net/publication/325735275> [accessed 22 March 2019].

Bhaskar, N.D., Lee, D.K.C. (2015). Bitcoin exchanges, [in:] D.K.C. Lee (ed.), Handbook of Digital Currency. Bitcoin, Innovation, Financial Instruments and Big Data. San Diego: Elsevier: $559-573$.

Bitcoincharts (2019). Exchange volume distribution. <https://bitcoincharts.com/charts/volumepie> [accessed 27 March 2019].

Black, F. (1971). Toward a fully automated stock exchange. Part I. Financial Analysts Journal 27(4): 25-35.

Brandvold, M., Molnár, P., Vagstad, K., Valstad, O. (2015). Price discovery on bitcoin exchanges. Journal of International Financial Markets. Institutions and Money 36: 18-35.

Brauneis, A., Mestel, R. (2018). Price discovery of cryptocurrencies: bitcoin and beyond. Economics Letters 165: 58-61.

Briere, M., Oosterlinck, K., Szafarz, A. (2015). Virtual currency, tangible return: portfolio diversification with bitcoin. Journal of Asset Management 16(6): 365-373.

Carrick, J. (2016). Bitcoin as a complement to emerging market currencies. Emerging Markets Finance and Trade 52(10): 2321-2334.

CoinMarketCap (2019). 24 Hour Volume Rankings (All Exchanges). <https://coinmarketcap.com/ exchanges/volume/24-hour/all/> [accessed 27 March 2019].

Dimpfl, T. (2017). Bitcoin market microstructure. <https://papers.ssrn.com/sol3/papers.cfm?abstract_id=2949807> [accessed 7 March 2018].

Doman, M. (2011). Mikrostruktura giełd papierów wartościowych. Poznań: Wydawnictwo Uniwersytetu Ekonomicznego w Poznaniu.

European Central Bank (2015). Virtual currency schemes - a further analysis. <https://www.ecb. europa.eu/pub/pdf/other/virtualcurrencyschemesen.pdf> [accessed 28 November 2018].

Glaser, F., Haferkorn, M., Siering, M., Weber, M.C., Zimmermann, K. (2014). Bitcoin - asset or currency? Revealing users' hidden intentions. Proceedings of the European Conference on Information Systems (ECIS). Tel Aviv.

Harris, L. (2003). Trading and Exchanges: Market Microstructure for Practitioners. Oxford: Oxford University Press.

Hileman, G., Rauchs, M. (2017). Global Cryptocurrency Benchmarking Study. Cambridge: Centre for Alternative Finance. 
Jonker, N. (2018). What drives bitcoin adoption by retailers? Working Paper no. 585. Amsterdam: De Nederlandsche Bank.

Lesmond, D.A. (2005). Liquidity of emerging markets. Journal of Financial Economics 77(2): $411-452$.

Loi, H. (2018). The liquidity of bitcoin. International Journal of Economics and Finance 10(1): $13-22$

Moore, T., Christin, N. (2013). Beware the middleman: empirical analysis of bitcoin-exchange risk, [in:] A. Sadeghi (ed.), Financial Cryptography and Data Security. Berlin: Springer: 25-33.

Nakamoto, S. (2008). Bitcoin: a peer-to-peer electronic cash system. < bitcoin.org/bitcoin.pdf> [accessed 21 December 2017].

Pandey, V.K., Wu, C.Y. (2014). The value of bitcoin in enhancing the efficiency of an investor's portfolio. Journal of Financial Planning 27(9): 44-52.

Piotrowska, A.I. (2018). Bitcoin. Płatnicze i inwestycyjne zastosowania kryptowaluty. Warszawa: CeDeWu.

Polasik, M., Piotrowska, A.I., Wiśniewski, T.P., Kotkowski, R., Lightfoot, G. (2015). Price fluctuations and the use of bitcoin: an empirical inquiry. International Journal of Electronic Commerce 20(1): 9-49.

Poskart, R. (2017). Giełdy bitcoina w Polsce. Przegląd Nauk Stosowanych 16: 113-125.

Shi, S. (2017). The impact of futures trading on intraday spot volatility and liquidity: evidence from bitcoin market. <https://ssrn.com/abstract=3094647> [accessed 3 April 2018].

Teo, E.G.S. (2015). Emergence, growth, and sustainability of bitcoin: the network economics perspective, [in:] D.K.C. Lee (ed.), Handbook of Digital Currency. Bitcoin, Innovation, Financial Instruments, and Big Data. San Diego: Elsevier: 191-200.

Thies, S., Molnár, P. (2018). Bayesian change point analysis of bitcoin returns. Finance Research Letters 27: 223-227.

Trimborn, S., Li, M., Härdle, W.K. (2017). Investing with cryptocurrencies - a liquidity constrained investment approach. SFB 649 Discussion Paper 2017-014.

Yermack, D. (2015). Is bitcoin a real currency? An economic appraisal, [in:] D.K.C. Lee (ed.), Handbook of Digital Currency. Bitcoin, Innovation, Financial Instruments and Big Data. San Diego: Elsevier: 31-43.

\section{LIQUIDITY OF BITCOIN - INSIGHTS FROM POLISH AND GLOBAL MARKETS}

$$
\text { Sum mary }
$$

Bitcoin can be exchanged for other cryptocurrencies as well as for fiat currencies on many different platforms. Nevertheless, its real convertibility may be limited by market liquidity. The main aim of this article is to characterize and compare big and small bitcoin markets in terms of liquidity. I examine four platforms with high trade volume: Kraken, Bitstamp, BitFlyer and BTCBOX, as well as small entities which enable bitcoin to be traded in Polish zloty: BitBay and BitMarket. I compare the number of trades and the time between trades on selected bitcoin markets, determine the volume distribution throughout the day and analyse the dynamics of Amihud's illiquidity measure - ILLIQ. I find that an exchange which is among the global leaders in terms of trading bitcoin in a particular traditional currency can be considered a smaller market in terms of trade volume in another traditional currency. Moreover, the results imply that BitBay and BitMarket can be perceived as local markets. They are mainly used for trading in Polish zloty, and are illiquid in terms of trading in the remaining traditional currencies. Home bias, the fact that they offer a possibility of trading in a less popular currency (in comparison to the world reserve currencies), and that have their interface in Polish, may give these platforms a competitive advantage.

Keywords: bitcoin; liquidity; Polish bitcoin market; JEL: G10, G23 
